\title{
Innovación creativa: The NOMAD Travelbox
}

\section{Pedro Fuentes-Duráa , Francisco Gaspar Quevedo ${ }^{b}$ y José Miguel Abarca Fernández}

aEscuela Técnica Superior de Ingeniería del Diseño, pfuentes@iqn.upv.es, bEscuela Técnica Superior de Ingeniería del Diseño, fragasqu@dib.upv.es y Escuela Técnica Superior de Ingeniería del Diseño, joabfer@dib.upv.es.

\begin{abstract}
EPS is taught in 12 countries in a multicultural, multilevel and multidisciplinary team based scheme. It's designed to develop essential transversal competences for employability in a global context. To date, 14 staff from 9 departments have already participated, in collaboration with companies, thereby generating added value to student exchange periods, creating an excellent environment for the reception of students and contributing to opportunities available. EPS' ongoing evolution is based on participant satisfaction and open innovation. This paper shows the Project developed by a student team against the challenge of design a solution to travel and sleep in your own car. From basic premises, students developed a complete process of thinking, design and application, concluding with a $100 \%$ functional prototype. Students developed creativity, effective communication, innovation skills and practical thinking.
\end{abstract}

Keywords: innovation, creativity, POL, European Project Semester.

\footnotetext{
Resumen

En EPS, impartido en 12 países, participan estudiantes en equipos multinivel, multidisciplinares y multiculturales. Su metodología POL está orientada a la adquisición de las competencias demandadas por la globalización. Actualmente se encuentra bajo estudio su impacto en las competencias transversales de la UPV. En la ETSID (UPV) ya han participado como supervisores 14 profesores de 9 departamentos diferentes en colaboración con diversas empresas, generando valor añadido a los periodos de intercambio, creando un ambiente excelente para la recepción de estudiantes y abriendo el abanico de oportunidades para los estudiantes de grado. Las encuestas de satisfacción e innovación abierta de los participantes soportan su continua evolución y mejora. En este trabajo se expone con detalle lo realizado por un equipo de estudiantes al aceptar el
}

(c)) EY-NC-ND 2015, Universitat Politècnica de València

Congreso In-Red (2015) 
reto de diseñar una solución que permitiese viajar y dormir en tu propio coche. A partir de unas premisas genéricas, los estudiantes desarrollan un proceso completo de pensamiento, diseño y aplicación, que concluye con un prototipo real 100\% funcional. En este periodo de tiempo, los estudiantes desarrollaron algunas competencias importantes como la creatividad, la comunicación efectiva, la innovación y el pensamiento práctico.

Palabras clave: innovación, creatividad, POL, European Project Semester.

\section{Introducción}

¿Cuáles son las herramientas fundamentales que deben enseñarse en educación superior y cómo deben ser "enseñadas"? Los empleadores asocian experiencia internacional y empleabilidad de un graduado, debido a la experiencia, los contactos, los idiomas y el desarrollo de "soft skills" relacionados con la multiculturalidad, las características personales y las formas de pensar. El European Project Semester (EPS) combina las ideas anteriores con el éxito de la metodología Project Based Learning. El EPS fue sido diseñado para preparar a ingenieros que afrontaran los retos de la economía mundial actual. Equipos de estudiantes internacionales trabajando en proyectos multidisciplinares, donde pueden desarrollar sus capacidades, así como sus habilidades de comunicación intercultural y trabajo en equipo. El EPS es un paquete formativo que se cursará el curso 2015/2016 en 17 Instituciones de Educación Superior desde Reino Unido a Rumanía y de Portugal a Finlandia. Se combina PBL con un conjunto de microcursos, seminarios y actividades de soporte. En él participan estudiantes de diferentes titulaciones y trabajan equipos multinivel, multidisciplinares y multiculturales. Está orientado a la adquisición de las competencias demandadas por la globalización y el rápido cambio actual (Hansen, 2010).

\section{Objetivos}

El objetivo principal es la adaptación del European Project Semester (EPS) como herramienta base para mejorar las "soft skills" de los graduados y profesores de la ETSID y crear un ambiente excelente para la recepción de alumnos de intercambio. En este caso, se escogió esta tipología de proyecto ya que buscábamos en los alumnos que pudiesen desarrollar y poner en práctica las siguientes habilidades: 1) Realización de una investigación previa, más allá de la temática del proyecto en la que estaban trabajando (el mundo "Camper", sistemas de plegado, la forma de viajar y las soluciones adoptadas, sector del camping, sistemas modulares, etc.). 2) Abordaje de todas las fases de desarrollo dentro del proceso de diseño de un producto industrial. 3) Capacidad de realizar un prototipo $100 \%$ funcional. 4) Abordaje del proyecto desde la perspectiva emprendedora de 
un producto autoeditado o autoproducido. Es decir que, una vez desarrollado, ellos mismos pudieran comercializarlo utilizando plataformas de micromecenazgo, por ejemplo.

\section{Desarrollo de la innovación}

Una serie de estudiantes del EPS Valencia 2014 se entusiasmó con el reto de diseñar una solución que permitiese viajar y dormir en tu propio coche. Las premisas del proyecto eran que, en la medida de lo posible, la solución fuese: Ligera, sencilla, económica, fácil de instalar y transformar, lo más universal y versátil posible (que sirviese para el máximo número de modelos diferentes de coche) y con posibilidad de añadir accesorios como, por ejemplo, un hornillo, depósito de agua, lavabo, nevera, etc.

Las razones que nos motivaron a ofrecer este briefing de desarrollo, se basaban en nuestra intención de proponer un proyecto con el cual los alumnos se sintiesen motivados e identificados, pudiendo relacionar el desarrollo del mismo con su vida o situación personal.

Para ello, entre otras cosas, pretendíamos que a nivel personal el proyecto estuviese orientado al mundo de los jóvenes, fuese económico de fabricar por ellos mismos, y que en última instancia les permitiese experimentar de forma directa un resultado final lo más cercano a la realidad que fuese posible, pudiendo entre otras cosas trabajar con un modelo a escala real.

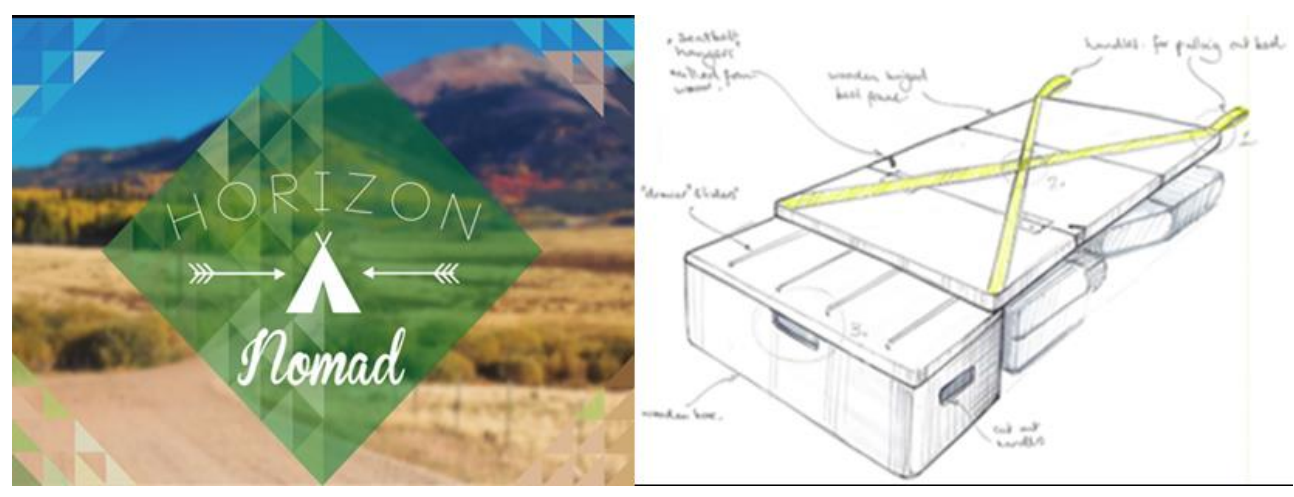

Fig. 1 Nombre e imagen elegida por los estudiantes para su proyecto (izquierda) y boceto de un original sistema de plegado (derecha)

Mediante las actividades oportunas (Gasch, 2012), los estudiantes establecieron el equipo y sus reglas, compartieron información para establecer su capacidad técnica y sus posibles roles, y diseñaron su nombre y su imagen. El equipo quedó compuesto por seis estudiantes de Bélgica, Francia, Holanda (2), Islandia y Reino Unido. Las titulaciones de los estudiantes eran Ingeniería Mecánica (2), Ingeniería del Diseño, Diseño Industrial, Ingeniería Industrial y Desarrollo de Producto. A través de BELBIN@ TEAM ROLE se 
estableció que el equipo estaba bastante equilibrado y muy social, y que sus principales debilidades eran la ausencia de carácter especialista y un nivel bajo de acción, por lo que se tomaron las acciones oportunas. El equipo fue liderado por dos perfiles muy interesantes, un coordinador muy crítico y un impulsor muy cerebral. Al tratarse de un equipo multidisciplinar, cada fase constituye una oportunidad para algunos componentes, según su responsabilidad en creatividad, o definición técnica de propuestas, o información relativa a normativas, herrajes y piezas estándar o estadísticas de usuarios, etc. La definición de tareas, su distribución y organización temporal se llevó a cabo mediante técnicas sencillas pero muy poderosas, como escenarios, WBS y diagrama de Gantt (Goodwin, 2009).

El proceso se llevó a cabo siguiendo un plan de 10 fases que se expone a continuación y en las que se da respuesta a unos objetivos docentes al tiempo que se simula un entorno real. En todas ellas se abre la opción de replantear algún avance si se considera que algo no funciona correctamente debido a la complejidad del proyecto, a la aparición de una incongruencia, etc. Todas las semanas el equipo se reunía con los supervisores para facilitar la orientación y la consecución de objetivos. En las reuniones se evaluaba la generación de conceptos y se controlaba la gestión del proyecto, adaptando el enfoque a la fase en la que se encontraba y teniendo en cuenta el perfil de los participantes.

\subsection{Estudio/Investigación de mercado}

Tras plantear a los alumnos el briefing inicial, comenzaron una búsqueda de información referente al proyecto siguiendo criterios relacionados con el usuario, modelos de vida, materiales, aplicaciones, así como referencias externas en cuanto a empresas fabricantes de este tipo de productos, productos o desarrollos similares, etc.

Toda esta información los alumnos la gestionaban y trabajan utilizando maquetaciones bajo el formato Moodboard que permite, de una forma ágil, gestionar, evaluar y seleccionar aquellos conceptos e ideas más relevantes para el proyecto (Hughes, 2008).

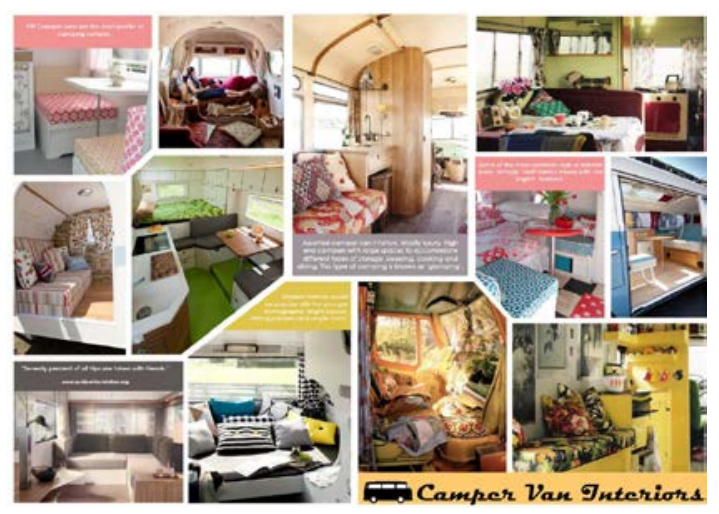

Fig. 2 Ejemplo de Moodboard de producto creado por el equipo

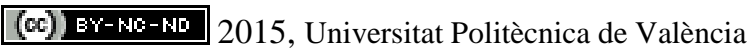

Congreso IN-RED (2015) 
Con propósito inmersivo y motivador, el equipo realizó un intenso trabajo de campo. El máximo exponente fue el Salón Internacional del Caravaning celebrado en Barcelona a través del cual pudieron tener un contacto directo con las últimas novedades de este sector, íntimamente relacionado con el proyecto que los alumnos debían desarrollar desde el punto de vista conceptual. Al estar en la primera fase, el conocimiento del equipo es crucial y, lógicamente, este tipo de actividad contribuye en gran medida a la creación y desarrollo del equipo, importantísimo para alcanzar el éxito en un programa como el EPS.

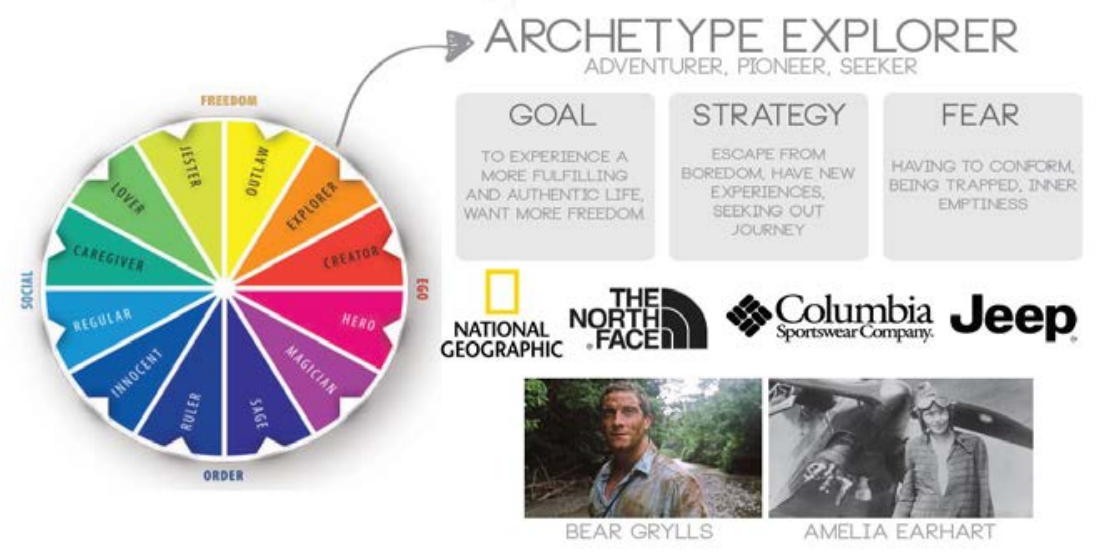

Fig. 3 Ejemplo de Moodboard referencial/clasificatorio creado por el equipo

Los estudiantes emplearon toma de notas, fotografías, vídeos así como experiencias en primera persona para conocer de primera mano las últimas innovaciones y aplicaciones en el sector del caravaning. Cabe destacar el know how adquirido en cuanto a la utilización y aplicación de materiales en este ámbito, tanto nuevos como tradicionales, y los resultados que sus características ofrecen.

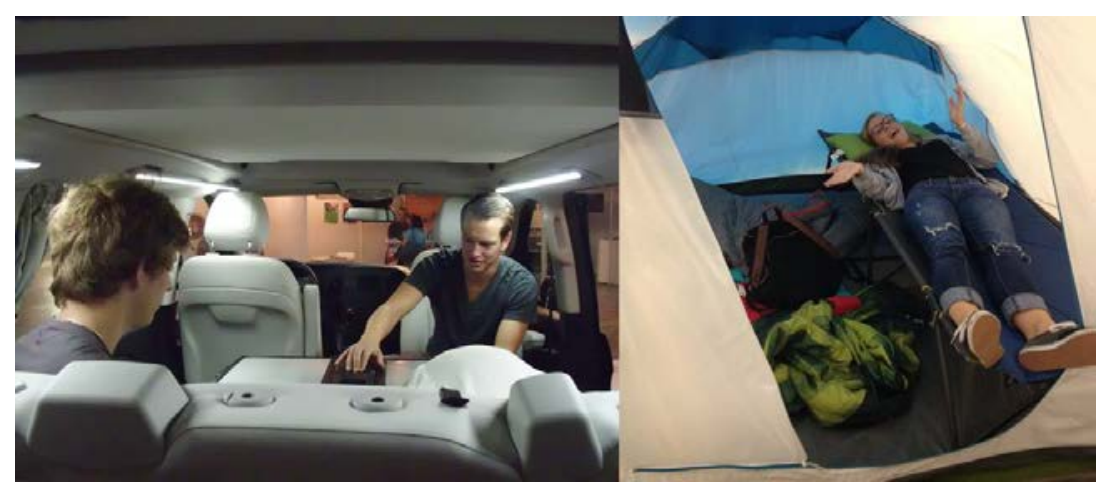

Fig. 4 Imágenes de la visita inmersiva

\section{(cc) EY-NC-ND 2015, Universitat Politècnica de València}

Congreso In-Red (2015) 
Las soluciones aportadas por diferentes fabricantes en cuanto a la conceptualización de mecanismos y volúmenes, permiten adquirir conocimientos respecto a la aplicación de estas soluciones, muy útiles para acometer con garantías de éxito el proyecto propuesto. Resumiendo, en esta importantísima primera fase los alumnos hicieron una recopilación, registro y análisis de datos relacionados con empresas del sector y su mercado, aproximándoles a las tendencias actuales en composiciones y versiones de producto. Este análisis, sistemático y objetivo, tiene la finalidad de suministrar toda información posible y necesaria a la hora de tomar decisiones en las siguientes fases del desarrollo.

Estudiaron: a) la gama completa de productos fabricados, suministrados o comercializados por las diferentes empresas o referencias consultadas; b) la metodología de trabajo empleada por estas referencias en cuanto al diseño y desarrollo de sus productos, con la finalidad de buscar afinidades y adaptaciones en el desarrollo que se llevará a cabo a posteriori; c) los posibles proveedores implicados en la fabricación de los productos de referencia; d) los materiales a utilizar en la fabricación de las diferentes soluciones o componentes; e) las diferentes técnicas de fabricación, montaje y ensamblaje aplicables al diseño (problemas detectados, soluciones aplicadas, posibles mejoras, etc.); f) los sectores afines, procesos y/o posibles técnicas no tradicionales aplicables a los futuros desarrollos (esto da un amplio margen de maniobra para las siguientes fases de diseño).

\subsection{Diseño de conceptos}

El equipo utilizó la tormenta de ideas en varias sesiones con organizadores gráficos para generar ideas al tiempo que creaban conocimiento gracias a la visualización estructurada (Hyerle, 1996). La información recopilada y la diversidad del equipo la hicieron muy fructífera. Se obtuvieron resultados que aunaban tanto soluciones conceptuales atípicas e innovadoras, como desarrollos en una línea más conservadora y previsible.

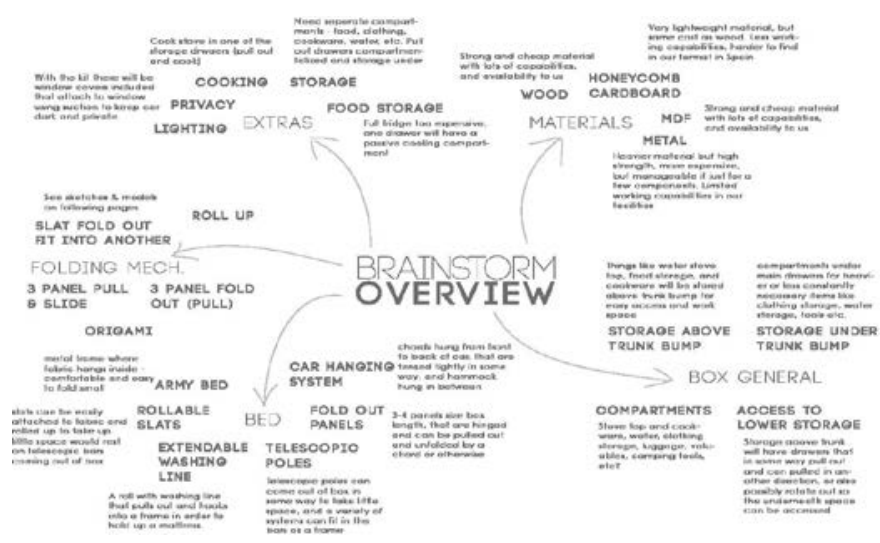

Fig. 5 Ejemplo de organizador gráfico de ideas generadas 
Los alumnos comienzan a seleccionar ideas y a realizar bocetos, al tiempo que aprovechan estas sesiones para tratar aspectos relativos a todos los condicionantes del proyecto (como posibles procesos productivos o aplicación de nuevos materiales), que será necesario trabajar ulteriormente pero aparecen de forma espontánea en estas fases tempranas.
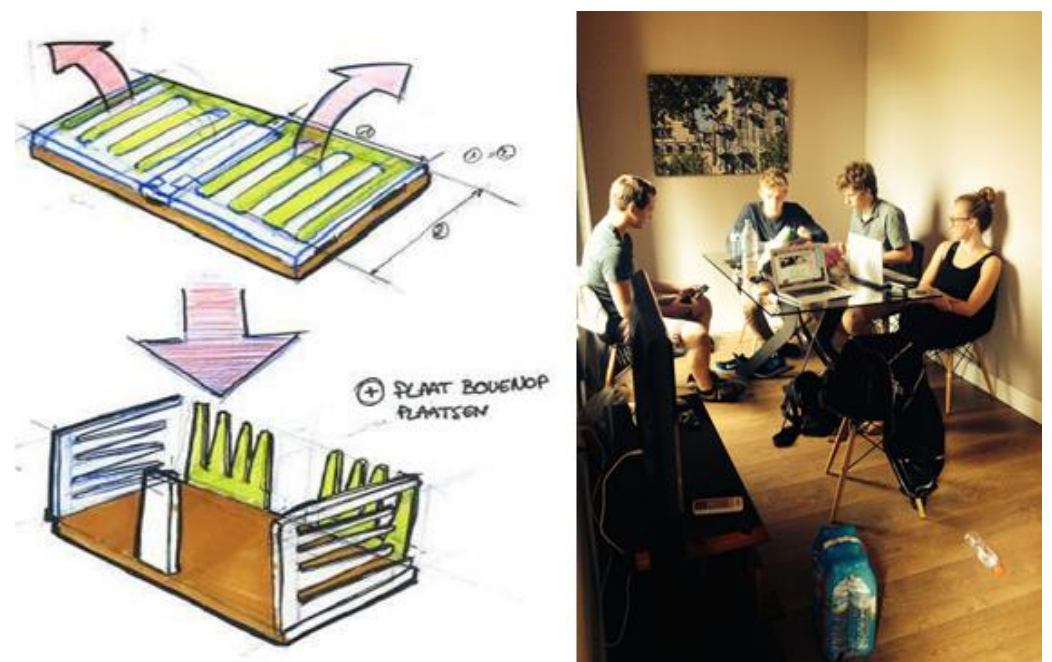

Fig.6 Boceto generado (izquierda) durante una sesión de brainwriting estructurada (derecha)
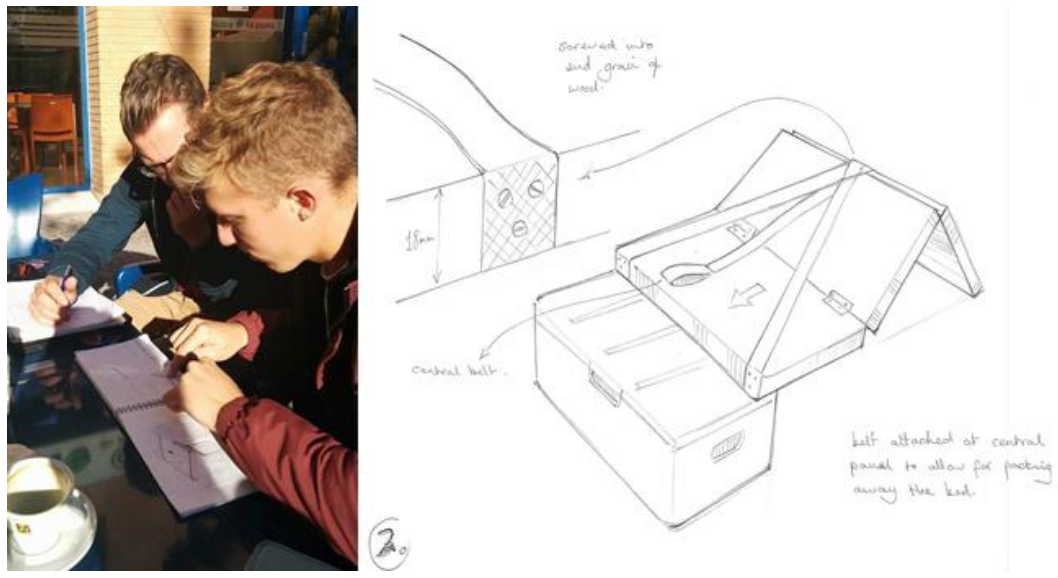

Fig. 7 Ejemplo de sesión de bocetado (izquierda) con representación de una idea prometedora (derecha)

\subsection{Diseño propuesto}

Los estudiantes desarrollan propuestas formales del desarrollo requerido. Para asegurar una adecuada comprensión por parte de todos ellos, así como facilitar el seguimiento por parte

\section{(c)) EY-NC-ND 2015, Universitat Politècnica de València}

Congreso In-Red (2015) 
de los supervisores de las diferentes soluciones de diseño presentadas, los alumnos documentan esta fase con bocetos y anotaciones que ilustran el proceso creativo, y generan imágenes virtuales (cada uno con el programa de modelado con el que tiene más capacidad), que representan y definen más fielmente las propuestas presentadas.

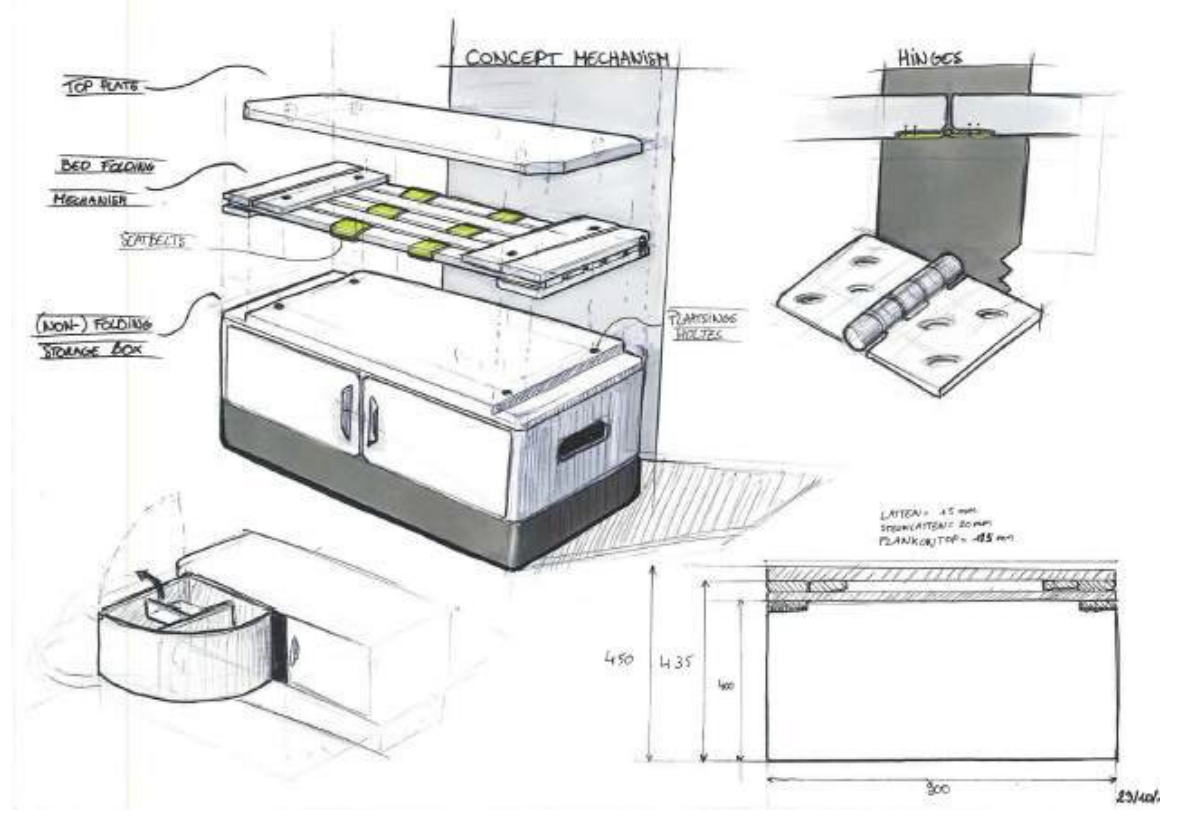

Fig. 8 Ejemplo de documentación de un diseño propuesto

El equipo aportó tres opciones de desarrollo, aunando todas ellas solucionares técnicas muy similares, pero exponiendo diferentes sistemas de almacenaje y plegado de los distintos componentes que conformaban los espacios de almacenaje y las áreas de servicio y/o uso.

\subsection{Pruebas y modelos previos}

En esta fase, se apartó a los alumnos de las herramientas informatizadas para explotar las posibilidades pedagógicas y de diseño del prototipado (Warfel, 2009). Se les invitó a que utilizaran un coche en miniatura para probar maquetas hechas con cartón pluma y comprobar su funcionamiento al desplegarse dentro de un volumen acotado. Esto les ayudó a poder evaluar de una manera más ágil la viabilidad de sus propuestas. Comienzan así test de volumen, ergonomía, espacio útil aplicable al desarrollo, etc. Para ello, realizan tanto modelos dimensionales simples a escala real en cartón (que se testeaban en vehículos reales), como pequeños modelos a escala 1:5 o 1:10 de posibles soluciones mecánicas en cuanto a abatimientos, pliegues o cierres de los distintos componentes. Simultáneamente, comenzaron a evaluar opciones de acabado, materiales, colores, etc. Usando la información 
recopilada en las primeras fases. Diferenciaron tres grandes grupos de materiales a utilizar: estructurales, aislantes y estéticos.
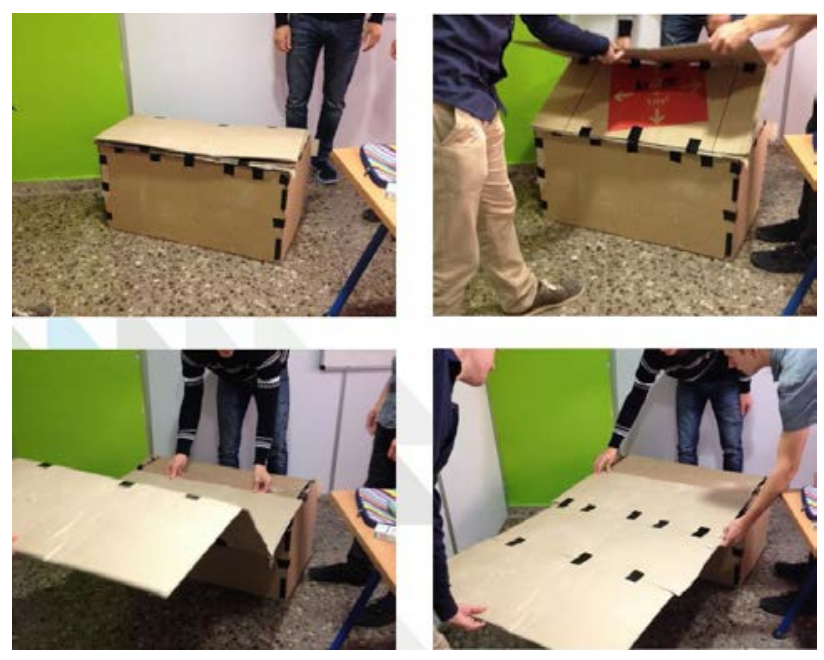

Fig. 9 Modelo a escala real en cartón
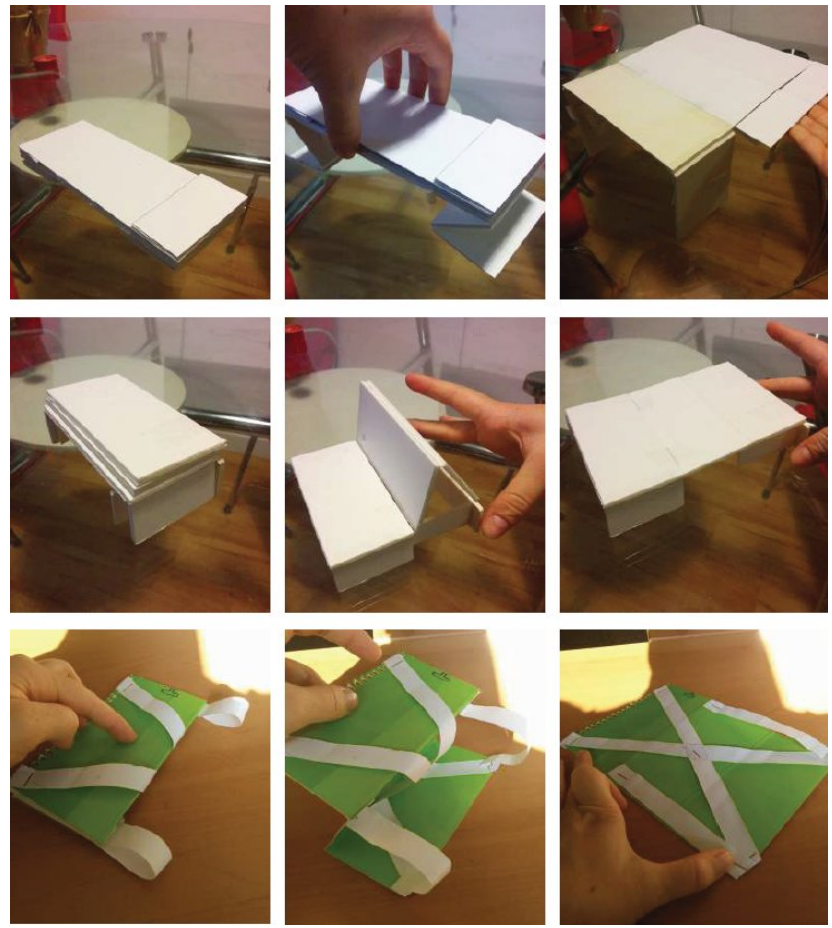

Fig. 10 Pruebas con modelos a escala 1:5 y 1:10

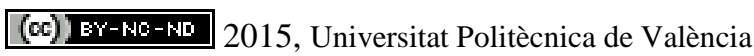

Congreso In-Red (2015) 


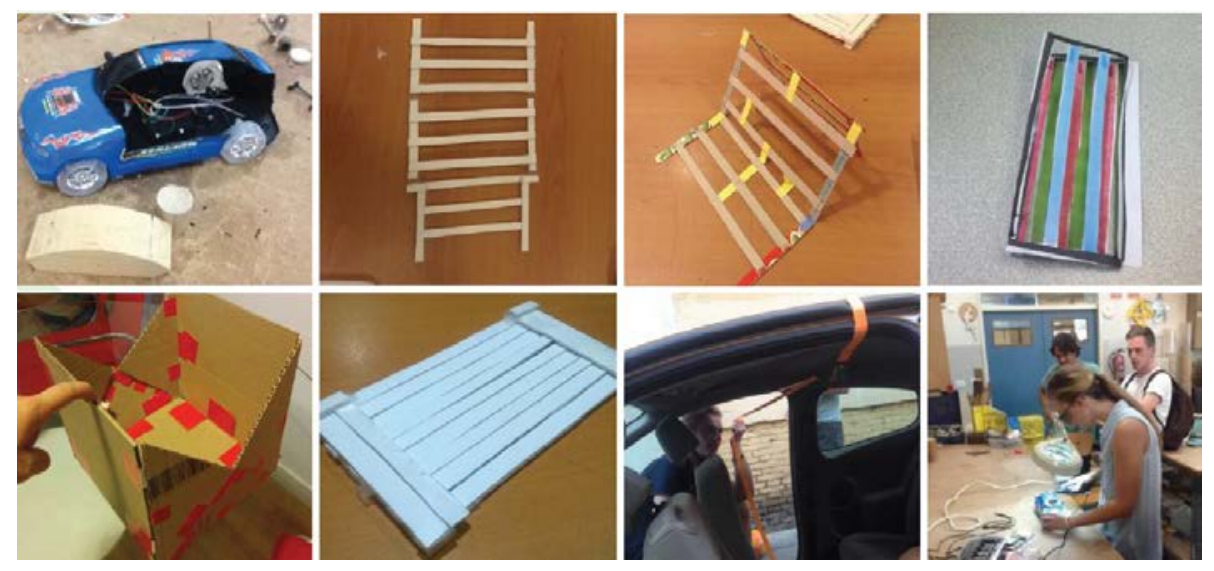

Fig. 11 Comprobación de soluciones mecánicas

\subsection{Diseño básico}

En esta fase se realizaron diseños paramétricos, planos básicos e imágenes virtuales que representaban y definían las propuestas seleccionadas. Se incorporaron cambios o mejoras gracias a lo percibido con los modelos en papel-cartón y con las pequeñas pruebas mecánicas.
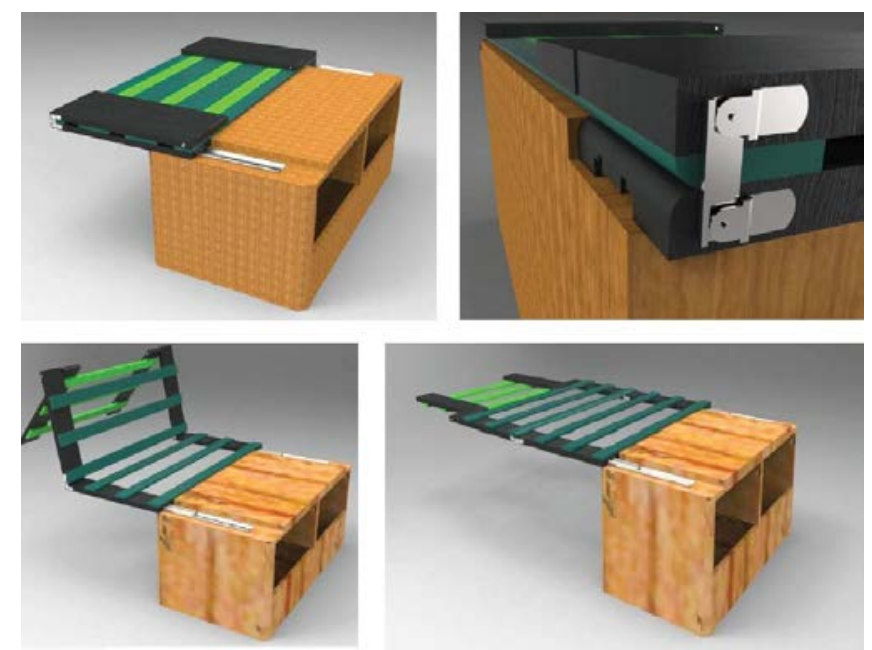

Fig. 12 Diseño básico

El equipo decidió usar Solidworks y elaboró un "proyecto básico” de su propuesta para la perfecta comprensión de los diseños seleccionados para desarrollar por parte de los supervisores, evaluadores y del propio grupo de trabajo. Mediante planos e imágenes 
virtuales se definen volúmenes y medidas de base, así como una primera aproximación en acabados y detalles. Así se pudo visualizar el producto y se proyectó al mismo tiempo medidas generales, rectificando en plano y corrigiendo futuros errores, asegurando de esta forma el resultado requerido hasta llegar a un producto válido.

\subsection{Desarrollo técnico}

En esta fase simularon el trabajo en la industria real, teniendo que proveer archivos Cad definidos al milímetro previamente por medio de ensamblajes virtuales a personas externas al equipo. El desarrollo seleccionado, está supeditado al análisis técnico de los elementos que conforman la solución adoptada, y en este punto los estudiantes optimizan el diseño del producto con el objetivo de estandarizar procesos y componentes y con la finalidad de abaratar costes en su producción posterior. El equipo ha de prever los condicionantes futuros y, entre otras acciones, debe desarrollar el diseño de los posibles útiles que fuese necesario fabricar para la obtención de piezas especiales (moldes de termoconformado, presas de anclaje para los bancos de trabajo, etc.). Propusieron opciones industriales distintas, proveedores alternativos para la fabricación u obtención de piezas o componentes, en la modificación o sustitución de componentes o en procesos sujetos a cambios.

Paralelamente, asumieron la responsabilidad de buscar proveedores de materias primas, herrajes, etc. De este modo, a pesar de las dificultades del idioma, los alumnos se vieron en la misma situación que estarían si ellos mismos quisieran producir su diseño sin apoyo institucional. El equipo se encargó de suministrar a los proveedores (técnico de taller y proveedores externos) la documentación en formato digital, así como las modificaciones necesarias para la ilustración y generación de instrucciones para la industrialización (aclaraciones en cuanto a ángulos de salida, radios mínimos, insertos metálicos, pesos, etc.).

\subsection{Adecuación a la producción}

En esta fase los alumnos realizan el diseño pormenorizado de todas y cada una de las partes de la solución aceptada, especificando en cada caso los materiales, las características superficiales y las referencias. Los alumnos detallan medidas exhaustivas teniendo en cuenta materiales, detalles constructivos, procesos productivos, costes, peso, etc. Se describe en profundidad la cantidad de partes y/o piezas que compondrán la solución estudiando el ensamblaje entre ellas, tolerancias, herrajes que se utilizarán, etc. Esto incluye planos y secciones que describen exhaustivamente cada una de las piezas con todas las cotas y anotaciones necesarias para su fabricación. Después de adquirir los elementos estándar y conocer las limitaciones existentes, bien productivas, bien de la materia prima adquirida, los cambios pertinentes en el Cad los realizó una sola persona.

\section{(cc) EY-NC-ND 2015, Universitat Politècnica de València}




\subsection{Fabricación de prototipo}

En esta fase los estudiantes se acercan a diversos aspectos profesionales como logística industrial, recursos humanos, estructura empresarial, estrategia de operaciones, diseño de detalle del producto, diseño técnico orientado a la producción, tolerancias de montaje, etc. Esto, unido a la responsabilidad de que todos los elementos funcionasen a la perfección, les obligó a pensar anticipadamente cada uno de los detalles que iba a tener el producto final (Buchenau, 2000). El personal del taller y los supervisores colaboran el equipo para asegurar la fidelidad a los planos y archivos generados en la fase de proyecto técnico, y analizan las posibles rectificaciones o sustituciones de piezas o componentes que puedan surgir debido a problemas de fabricación, costes, suministro u otros imprevistos.

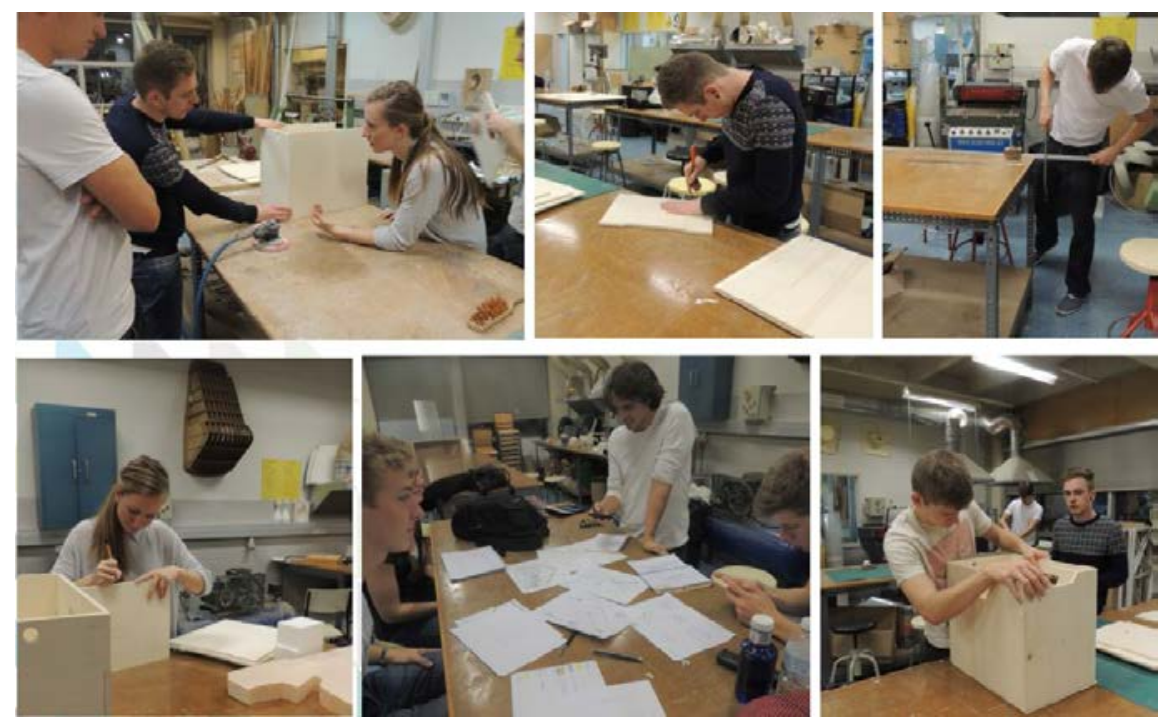

Fig. 13 Fabricación del prototipo final

\subsection{Mejoras}

Con el prototipo definido en un 95\% se vieron aspectos del mismo que son muy difíciles de prever en los ensamblajes virtuales y que desvelaron posibles mejoras en el producto que se llevaron a cabo. Los supervisores (aportando una visión profesional) cooperaron en las modificaciones necesarias y en la rectificación y corrección de piezas y procesos. También se optimizó la lista de proveedores para asegurar la obtención del producto.

\subsection{Presentación Final}

La presentación final consistió en una exposición pública donde argumentaron los resultados del modelo que, en directo, manipulaban y presentaban a la audiencia. También 
se realizó un póster, un video descriptivo del trabajo realizado y el oportuno dossier, por lo que fue una gran oportunidad para que los participantes explotaran al máximo habilidades técnicas en fotografía o renderización y destrezas comunicativas. La comunicación del desarrollo previa en las diferentes sesiones de control implicó un trabajo de documentación continua de imágenes fotográficas, modelos virtuales, modelos fotorrealistas en 3D y fotocomposiciones que maquetaban en el portafolio del equipo. También realizaron un video promocional de su propuesta, en el cual podía observarse tanto el aspecto estético y apariencia del modelo, como la forma de uso y aplicación directa, y las distintas opciones y características que presentaba el producto desarrollado.
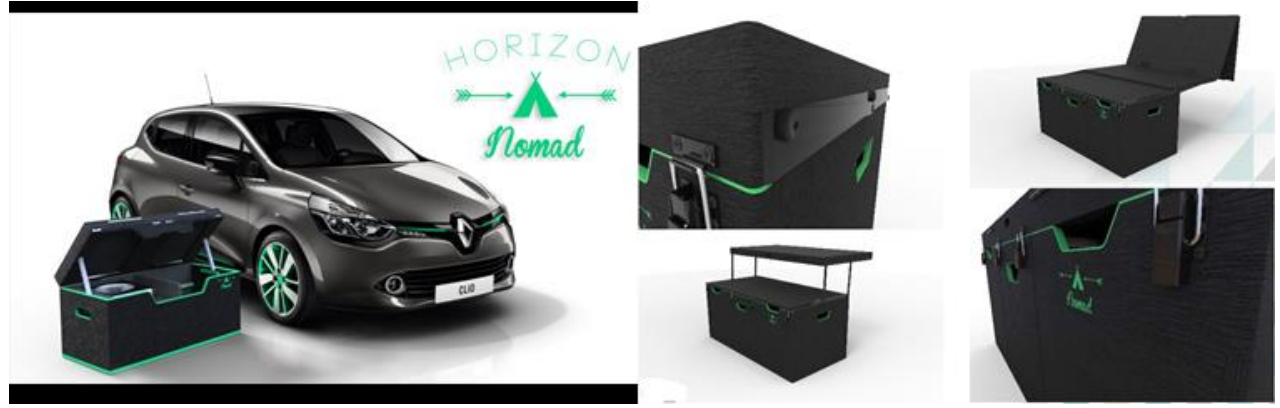

Fig.14 Modelo fotorrealista en 3D del producto final

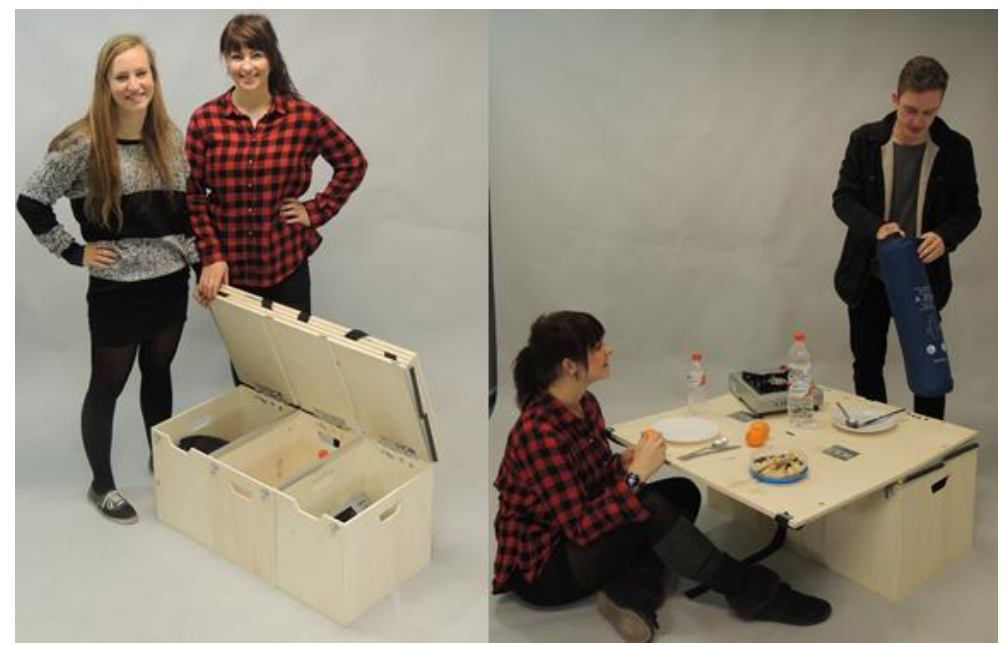

Fig.15 Fotografías que ilustran el producto final

\section{Resultados}

Queremos descartar que, inspirados en nuestra experiencia 3 socios internacionales van a comenzar a impartir EPS en el curso 2015/2016: Glasgow Caledonian University, Hochschule Osnabrück y Nottingham Trent University.

\section{(cc) EY-NC-ND 2015, Universitat Politècnica de València}


Entre los principales resultados podemos citar: 1) Un equipo muy motivado por superar un reto que habían elegido y que consideraban próximo y relevante. 2) Una completísima investigación acompañada de una adecuada inmersión y un proceso generativo brillante. 3) Un proceso complejo de desarrollo del producto aplicando todas las fases del Design Thinking (Vianna et al., 2012). 4) Un prototipo a tamaño real completamente funcional. 5) Una actitud netamente emprendedora por parte de algunos participantes. 6) Un elevado grado de satisfacción. 7) Una valoración muy positiva de los logros por parte de los participantes y de los evaluadores externos. La tabla 1 resume las valoraciones cuantitativas de las competencias diana.

Tabla 1. Resultados medios (n=6) de la evaluación de competencias por parte de los diferentes actores ( 3 supervisores, 5 externos, 41 pares). Máximo diez puntos.

\begin{tabular}{lccc}
\hline \multicolumn{1}{c}{ Competencia transversal } & Supervisores & Externos & Pares \\
\hline Recogen adecuadamente la información disponible & 10 & 9,2 & 7,8 \\
Aplican los conocimientos a la práctica de forma eficaz & 9.3 & 9,8 & 7,7 \\
Establecen un proceso para alcanzar los objetivos de forma & 8.7 & 9 & 8 \\
eficiente & & & \\
Utilizan correctamente técnicas de creatividad & 9 & 8,8 & 7,3 \\
Integran conocimiento complejo para generar ideas & 10 & 8,5 & 7,9 \\
novedosas & & & \\
Tienen en cuenta cómo afecta la innovación & 8.9 & 8,5 & 7 \\
Muestran una actitud emprendedora & 9 & 8,9 & 6,8 \\
Comunican efizcamente la información técnica & 9 & 9,4 & 7,8 \\
\hline
\end{tabular}

Por último, queremos recoger la opinión de los supervisores con experiencia profesional en diseño (http://www.discoh.com/): “Consideramos innegable la ventaja académica del EPS al aprovechar la heterogeneidad de las distintas formaciones, habilidades y objetivos de los participantes, ya que repercute muy positivamente en la ejecución de la solución aportada. Las diferentes metodologías de trabajo que los alumnos desarrollaron de forma independiente en sus respectivas universidades, se han puesto en común bajo esta actividad y han resultado en este proyecto, una herramienta formidable para el aprendizaje común, el conocimiento compartido, y la valoración personal de las capacidades y conocimientos que cada uno poseía previamente, y que sin lugar a dudas se ha visto incrementado tras esta experiencia. Esta convergencia de oportunidades ha dotado a los alumnos de una inestimable experiencia de trabajo en equipo y gestión compartida, que les resultará muy útil en el escenario laboral que formará parte de su inmediato desarrollo como futuros profesionales de éxito. No menos importante es el resultado de una experiencia vital que 
estrecha lazos, abre puertas a la comunicación y el entendimiento, supone en los participantes el punto de partida de una amistad y ha propiciado un clima de trabajo que ha favorecido en gran medida la creatividad, la motivación y en consecuencia unos resultados excelentes. Es muy probable que estas relaciones desemboquen en vínculos profesionales.”

\section{Conclusiones}

El análisis de las actividades desarrolladas arroja un balance muy positivo, que recomienda la continuidad del EPS. Los participantes están satisfechos, existe un interés internacional (alumnos potenciales, universidades socias y empresas multinacionales) y la UPV está apoyando decididamente el EPS. Los profesores que participan en EPS se desarrollan en el campo de la innovación educativa, sobre todo en lo referente a la multiculturalidad, la multidisciplinariedad, la comunicación y el trabajo en equipo.

EPS está en continua evolución y mejora gracias al proceso de innovación abierta apoyado en los participantes y en la colaboración de una extensa y diversa red internacional. El EPS constituye un atractivo singular para los estudiantes de intercambio lo que permite fortalecer las relaciones bilaterales con prestigiosas universidades. EPS crea un ambiente propicio para el desarrollo y evaluación de competencias transversales, como la aplicación del pensamiento práctico, la innovación o la comunicación efectiva.

\section{Referencias}

BUCHENAU, M. y SURI, J.F. (2000). “Experience Prototyping”. En Proceedings of Designing Intereactive Systems, ACM: 424-433.

GASCH, I., FUENTES-DURÁ, P. y PERRY, D. (2012). “European Project Semester” en Jornadas de Innovación Educativa 2012. Valencia: UPV. 132-136.

GOODWIN, K. (2009). Design in the Digital Age: How to Create Human-Centered Products and Services. Indianapolis: Wiley \& Sons.

HANSEN, J. (2010). "European Project Semester - how engineering students can achieve important competences”. En Proceedings of ICEE, Gliwice, Poland.

HUGHES, K. (2008). “Design to Promote Agency and Self-efficacy through Educational Games”. En Kafai, Y.B., Heeter, C., Denner, J., Sun, J.Y. Cambridge, MIT Press: 231-236.

HYERLE, D. (1996). Visual Tools for Constructing Knowledge. Alexandria: ASDC.

VIANNA, M. et al. (2012). Design Thinking. Rio de Janeiro: MJV Press.

WARFEL, T.Z. (2009). Prototyping: A Practicioner's Guide. Brooklyn: Rosenfeld Media. 